\title{
Myocardial Engineering in Vivo: Formation and Characterization of Contractile, Vascularized Three-Dimensional Cardiac Tissue
}

\author{
RAVI K. BIRLA, Ph.D., ${ }^{1}$ GREGORY H. BORSCHEL, M.D., ${ }^{2}$ ROBERT G. DENNIS, Ph.D., ${ }^{1-5}$ \\ and DAVID L. BROWN, M.D., F.A.C.S. ${ }^{2}$
}

\begin{abstract}
Engineering cardiac tissue in three dimensions is limited by the ability to supply nourishment to the cells in the center of the construct. This limits the radius of an in vitro engineered cardiac construct to approximately $40 \mu \mathrm{m}$. This study describes a method of engineering contractile three-dimensional cardiac tissue with the incorporation of an intrinsic vascular supply. Neonatal cardiac myocytes were cultured in vivo in silicone chambers, in close proximity to an intact vascular pedicle. Silicone tubes were filled with a suspension of cardiac myocytes in fibrin gel and surgically placed around the femoral artery and vein of adult rats. At 3 weeks, the tissues in the chambers were harvested for in vitro contractility evaluation and processed for histologic analysis. By 3 weeks, the chambers had become filled with living tissue. Hematoxylin and eosin staining showed large amounts of muscle tissue situated around the femoral vessels. Electron micrographs revealed well-organized intracellular contractile machinery and a high degree of intercellular connectivity. Immunostaining for von Willebrand factor demonstrated neovascularization throughout the constructs. With electrical stimulation, the constructs were able to generate an average active force of $263 \mu \mathrm{N}$ with a maximum of $843 \mu \mathrm{N}$. Electrical pacing was successful at frequencies of 1 to $20 \mathrm{~Hz}$. In addition, the constructs exhibited positive inotropy in response to ionic calcium and positive chronotropy in response to epinephrine. As engineering of cardiac replacement tissue proceeds, vascularization is an increasingly important component in the development of three-dimensional structures. This study demonstrates the in vivo survival, vascularization, organization, and functionality of transplanted myocardial cells.
\end{abstract}

\section{INTRODUCTION}

C Ongestive heart fallure (CHF) is a major medical challenge, with 4.9 million patients in the United States currently suffering from its effects. ${ }^{1}$ The economic cost associated with CHF is estimated to be $\$ 27.9$ billion annually. ${ }^{1}$ Current therapeutic strategies used to treat CHF include pharmaceutical intervention, ${ }^{2}$ mechanical cardiac support, ${ }^{3}$ and heart transplantation. ${ }^{4}$ Although these treatments have significantly improved the quality of patient care, there is a need for improved options. For example, heart transplantation has been the most suc-

\footnotetext{
${ }^{1}$ Department of Biomedical Engineering, University of Michigan, Ann Arbor, Michigan.

${ }^{2}$ Section of Plastic and Reconstructive Surgery, University of Michigan, Ann Arbor, Michigan.

${ }^{3}$ Department of Mechanical Engineering, University of Michigan, Ann Arbor, Michigan.

${ }^{4}$ Institute of Gerontology, University of Michigan, Ann Arbor, Michigan.

${ }^{5}$ Harvard-MIT Division of Health Sciences \& Technology, Cambridge, Massachusetts.
} 
cessful modality in the treatment of severe CHF, with more than 55,000 heart transplantations being performed as of March 2001. Heart transplantation has a high success rate with a short-term survival of $81 \% .{ }^{4}$ However, widespread applicability is limited by the chronic shortage of donor organs. ${ }^{5}$

Cardiac tissue engineering may offer an alternative treatment modality for $\mathrm{CHF}$ by providing tissues to replace ischemic or scarred myocardium. Engineered myocardial tissue could also be used to patch myocardial septal defects and for reconstruction of congenital cardiac anomalies. In addition to its potential clinical applicability, engineered three-dimensional cardiac tissue could be useful as a system for basic cardiology research and as a means to evaluate efficacy and safety in new drug development.

There have been several strategies utilized to engineer three-dimensional cardiac tissue constructs. Temperature-sensitive surfaces have been used to manufacture two-dimensional monolayers of cardiac myocytes, which can then be stacked together to form three-dimensional cardiac muscle constructs. ${ }^{6-8}$ Synthetic scaffolds fabricated from polyglycolic acid have been used to generate three-dimensional constructs by seeding with neonatal cardiac myocytes. ${ }^{9-11}$ In addition, others have investigated various biodegradable gel systems consisting of gelatin, ${ }^{12-14}$ alginate, ${ }^{15}$ and collagen. ${ }^{16-19}$

We have previously described an in vitro method for engineering cardiac tissue from neonatal cardiac myocytes. $^{20}$ The resulting three-dimensional tissue constructs, which we termed "cardioids," can be electrically stimulated to generate an active force of $75 \mu \mathrm{N}$. In addition, we demonstrated that these cardioids can be electrically paced at frequencies of up to $100 \mathrm{~Hz}$ without fused tetanus. Cardioids exhibit positive inotropy in response to ionic calcium and positive chronotropy in response to epinephrine. However, these cardiac tissue analogs are limited in size because of the restraints of diffusion within these avascular tissue constructs.

The diffusion of oxygen places a major design constraint on all avascular engineered tissues. Angiogenesis becomes necessary to engineer tissue constructs with a diameter greater than $200 \mu \mathrm{m}^{21}$ Therapeutic angiogenesis is the process by which local growth of blood vessels is induced by various interventions, resulting in neovascularization of engineered constructs. ${ }^{22,23}$ There are several strategies that have resulted in initial success at therapeutic angiogenesis in engineered constructs. Incorporation of angiogenic factors, ${ }^{24,25}$ seeding of endothelial cells, ${ }^{26}$ prevascularization of the scaffold before cell seeding, ${ }^{27}$ and the use of solid free-form fabrication ${ }^{28,29}$ have all been evaluated.

One novel approach to introducing a vascular supply to three-dimensional engineered tissues has been shown to support survival and function of engineered tis- sues. ${ }^{30-33}$ Angiogenesis from arteriovenous loop and flow-through vascular pedicle models has been demonstrated to result in the creation of a newly formed "flap" of tissue. This model has been shown to support pancreatic islet cells and adipocytes. ${ }^{34,35}$ These findings lend support to the utilization of these models as a potential platform for three-dimensional myocardial tissue engineering.

In the current study, the in vivo models described above were modified and utilized to engineer three-dimensional contractile cardiac tissue with an intrinsic vascular supply.

\section{MATERIALS AND METHODS}

Approval for animal use was granted by the University Committee for the Use and Care of Animals (UCUCA) in accordance with the Guide for the Care and Use of Laboratory Animals (NIH publication 86-23, 1986). All materials were purchased from Sigma (St. Louis, MO) unless otherwise specified.

\section{Isolation of neonatal cardiac myocytes}

Cardiac myocytes were isolated from 2- to 3-day-old F344 rat hearts by an established method. ${ }^{36}$ Hearts were cut into fine pieces and suspended in dissociation solution (DS) consisting of collagenase type II $(0.32 \mathrm{mg} / \mathrm{mL}$; Worthington Biochemical, Lakewood, NJ) and pancreatin $(0.6 \mathrm{mg} / \mathrm{mL})$ dissolved in buffer consisting of 116 $\mathrm{mM} \mathrm{NaCl}, 20 \mathrm{mM}$ HEPES, $1 \mathrm{mM} \mathrm{Na}{ }_{2} \mathrm{HPO}_{4}, 5.5 \mathrm{mM}$ glucose, $5.4 \mathrm{mM} \mathrm{KCl}$, and $0.8 \mathrm{mM} \mathrm{MgSO}_{4}$. Digestion was carried out in an orbital shaker for $5 \mathrm{~min}$ at $37^{\circ} \mathrm{C}$, after which the supernatant was replaced with fresh DS and the digestion process was continued for an additional $30 \mathrm{~min}$. At the end of the digestion process, the supernatant was collected in $5 \mathrm{~mL}$ of horse serum (Invitrogen, Auckland, New Zealand) and centrifuged at $1500 \mathrm{rpm}$ for $5 \mathrm{~min}$, and the cell pellet was resuspended in $5 \mathrm{~mL}$ of horse serum. Fresh DS was added to the original, undigested tissue and the digestion process was repeated an additional two or three times. Cells from all the digests were pooled, centrifuged, and then suspended in plating medium consisting of $335 \mathrm{~mL}$ of Dulbecco's modified Eagle's medium (DMEM), $85 \mathrm{~mL}$ of M199, $25 \mathrm{~mL}$ of fetal bovine serum, $50 \mathrm{~mL}$ of horse serum, and $5 \mathrm{~mL}$ of antibiotic-antimycotic (Invitrogen). The total number of cells was determined with a hemocytometer.

\section{Preparation of chambers for implantation}

Silicone tubing (Cole-Parmer, Vernon Hills, IL), 1.6 $\mathrm{mm}$ (inner diameter) by $3.1 \mathrm{~mm}$ (outer diameter), with a wall thickness of $0.75 \mathrm{~mm}$, was cut to lengths of $10 \mathrm{~mm}$, making an internal volume of $50 \mu \mathrm{L}$. A longitudinal slit was made down the length of each tube to allow it to be 
opened length-wise for placement around the intact femoral vessels. Previously isolated cardiac myocytes were suspended in fibrin gel $(200 \mu \mathrm{L}$ of fibrinogen [3.5 $\mathrm{mg} / \mathrm{mL}]$ with $5 \mu \mathrm{L}$ of thrombin $[200 \mathrm{U} / \mathrm{mL}]$ ) at a concentration of 20 million cells per $50 \mu \mathrm{L}$ of gel. Fifty microliters of the suspension was pipetted into each of six vertically oriented silicone tubes and allowed to gel. Six control constructs were made without cells.

\section{Implantation and retrieval of chambers}

Six myocyte-seeded chambers and six control chambers were implanted. Adult F344 rats, weighing approximately $230-270 \mathrm{~g}$, were used as recipients. The animals were anesthetized by intraperitoneal injection of $0.5 \mathrm{~mL}$ of sodium pentobarbital (Abbott Laboratories, Chicago, IL). The groins were clipped of hair and sterilely prepared and draped. The femoral vessels were exposed through a longitudinal incision made on the medial thigh. With the aid of a dissecting microscope, the femoral artery and vein were separated from their surrounding tissue attachments and the accompanying nerve. Several small vascular branches to the thigh musculature were cauterized to isolate the length of the vessels from the inguinal ligament to the branch point of the epigastric vessels. The previously prepared myocyte-fibrin gel-filled tubes were placed around the femoral vessels, by passing the intact vascular pedicle through the slit in the side of the tubes (Fig. 1). The wounds were closed in two layers and the animals were allowed to recover.

After 3 weeks, the rats were reanesthetized and the chambers were isolated. Patency of the vascular pedicles was confirmed by visually monitoring the blood flow through the vessels. The femoral artery, femoral vein, and

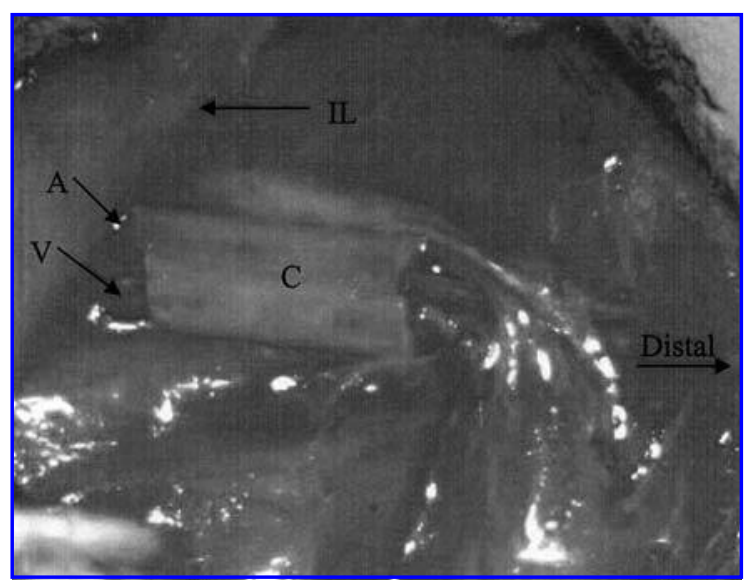

FIG. 1. Implantation of chambers. Silicone chambers (C) containing a fibrin gel suspension of neonatal cardiac cells (versus control chambers, with no added cells) were implanted around the femoral artery (A) and vein (V) in the groins of rats and left in vivo for 3 weeks. IL, inguinal ligament.

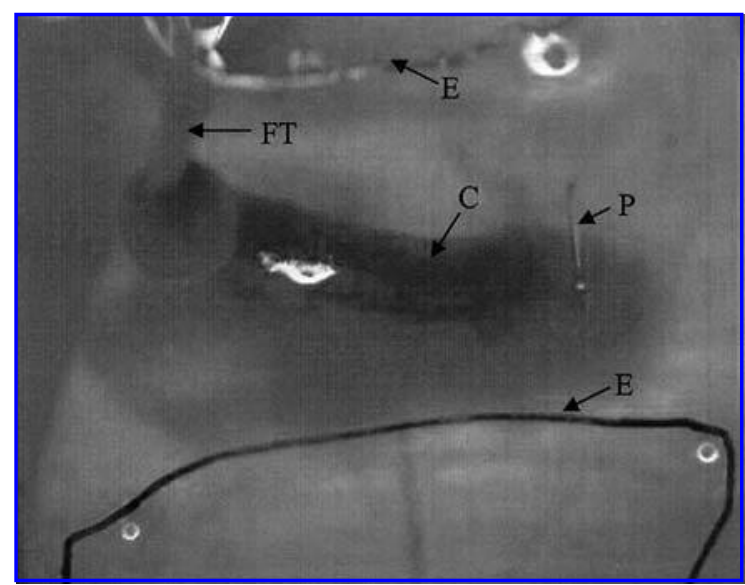

FIG. 2. Tissue harvest and in vitro force testing. Cylindershaped tissue constructs $(C)$ were removed from chambers at 3 weeks. They were placed in a bath of culture medium with one end pinned stationary to the culture plate $(\mathrm{P})$ and the other end attached to a force transducer (FT). Stimulation was accomplished with parallel platinum electrodes (E). The spontaneous and stimulated forces generated were recorded.

all soft tissue attachments were divided at the proximal and distal ends of the chambers. The chambers were opened along their longitudinal slit and tissues within them were removed and pinned to $35-\mathrm{mm}$ tissue culture plates coated with polydimethylsiloxane (Dow Chemical, Midland, MI) substrate. Culture medium (CM) consisting of $365 \mathrm{~mL}$ of DMEM, $100 \mathrm{~mL}$ of M199, $35 \mathrm{~mL}$ of fetal bovine serum, and $5 \mathrm{~mL}$ of antibiotic-antimycotic (Invitrogen) was added to the plates. The contractility of the tissues was determined as described below.

\section{Evaluation of contractility}

The method for evaluating the contractility of engineered skeletal muscle has been described in detail. ${ }^{37,38}$ This method was modified slightly. Briefly, the constructs were placed in $\mathrm{CM}$ at $37^{\circ} \mathrm{C}$, between parallel platinum electrodes (Fig. 2). One end was fixed to the plate and the other end was attached to a custom-built optical force transducer. Stimulated twitch force measurements were then recorded at $5 \mathrm{~V}$ and a $10-\mathrm{ms}$ pulse width. The length of each construct was adjusted to obtain maximum active force, using a multiaxis micromanipulator. This optimal length was designated as $L_{\mathrm{O}}$ and was recorded. The cross-sectional area of the constructs was calculated from the construct diameter, which was determined with a calibrated eyepiece reticle with a resolution of $5 \mu \mathrm{m}$. Initial stimulation parameters were selected on the basis of our previous experience with engineered cardiac muscle constructs. The stimulation parameters had been optimized for this system in pilot experiments performed previously. The constructs were electrically paced at fre- 
quencies of 1 to $20 \mathrm{~Hz}$, with all other stimulation parameters remaining constant. The active twitch force and the pacing characteristics were determined for experimental and control constructs. The six experimental constructs were then divided into three groups of two constructs for further testing. Two constructs were utilized to evaluate detailed length-force characteristics, two were utilized to evaluate calcium sensitivity behavior, and two were processed for histological evaluation. The constructs that were utilized for length-force and calcium sensitivity were pooled and used to evaluate their responsiveness to epinephrine.

The length-force relationship was investigated in two constructs. The equilibrium length-force relationship was evaluated by gradually increasing the distance between the two ends of the constructs as loaded on the force transducer, beginning at the resting length of the construct. Stimulated force measurements were obtained at each specimen length and were compared with the optimal length $L_{\mathrm{o}}$.

The effect of the addition of calcium on contractility was investigated in two constructs. First, CM in the bath was replaced with calcium-free DMEM (Invitrogen). Known volumes of $100 \mathrm{mM}$ ethylene glycol-bis(2aminoethylether)- $N, N, N^{\prime}, N^{\prime}$-tetraacetic acid (EGTA) were then added to the bath to bind residual stores of calcium in the constructs. At each incremental addition of EGTA twitch stimulation was applied and the force of contraction was measured. Removal of calcium was considered to be complete when the force of contraction was not detectable and no further EGTA was added. At this point, the calcium-free DMEM in the bath was aspirated and the construct was washed three times with fresh calcium-free DMEM. Known volumes of $100 \mathrm{mM}$ calcium were then added and stimulated contraction forces were reevaluated with each addition. This process was repeated until there was no further increase in the active force with the addition of calcium. The relationship of calcium concentration of the bath to force of contraction was then plotted.

The response to epinephrine was studied in four constructs by adding known concentrations of epinephrine to the $\mathrm{CM}$, with the constructs still attached to the force transducer. By the start of this portion of testing, the constructs had ceased to exhibit spontaneous contractions. The fluid in the bath was exchanged with fresh CM. Epinephrine was introduced by adding $8 \mu \mathrm{L}$ of an epinephrine solution $(0.1 \mathrm{mg} / \mathrm{mL})$ in $4 \mathrm{~mL}$ of DMEM to give a final concentration of $0.2 \mu \mathrm{g} / \mathrm{mL}$. The concentration of epinephrine was calculated on the basis of the typical dose given to an adult for cardiac resuscitation. The spontaneous contractility of the constructs was recorded for a period of $5 \mathrm{~min}$ after the addition of epinephrine.

\section{Histology}

After force testing, constructs were fixed in $4 \%$ paraformaldehyde for $4 \mathrm{~h}$ and stored in $70 \%$ ethanol. The constructs were prepared in an automated tissue processor (Shandon Hypercenter XP; Thermo Electron, Waltham, MA) and then paraffin embedded. Seven-micron-thick sections were cut and placed on ProbeOn Plus slides (Fisher Scientific, Pittsburg, PA). Hematoxylin and eosin (H\&E) staining was used for morphologic analysis of the constructs. To identify and localize endothelial cells, immunohistochemical staining for von Willebrand factor $(\mathrm{vWF})$ was performed. The slides were heated in an oven at $60^{\circ} \mathrm{C}$ for $20 \mathrm{~min}$. The heated slides were then placed in three changes of xylene, $100 \%$ ethanol, $95 \%$ ethanol, and buffer to prepare for staining. Antigen retrieval was performed for the slides designated for vWF staining by applying proteinase K (DakoCytomation, Carpinteria, CA) for $5 \mathrm{~min}$ at room temperature. The primary antibody (vWF antibody, polyclonal rabbit anti-human; DakoCytomation) was incubated at a dilution of 1:250 at room temperature for $30 \mathrm{~min}$. The Envision + peroxidase kit (DakoCytomation) was used for detection. Sections were viewed and photographed with a Nikon Axiophot inverted phase-contrast microscope.

\section{Electron microscopy}

The method used for electron microscopy has been previously described. ${ }^{37,38}$ Briefly, constructs were fixed for $4 \mathrm{~h}$ at $4^{\circ} \mathrm{C}$ in Karnovsky's solution consisting of $0.1 \mathrm{M}$ sodium cacodylate buffer with 3\% formaldehyde and 3\% glutaraldehyde (Electron Microscopy Sciences, Fort Washington, PA) at $\mathrm{pH}$ 7.4. Constructs were rinsed three times (30 min, $30 \mathrm{~min}$, and $4 \mathrm{~h}$ ) with cacodylate buffer, $\mathrm{pH} 7.4$, with $7.5 \%$ sucrose. They were postfixed in $1 \%$ osmium tetroxide for $2 \mathrm{~h}$ at room temperature, dehydrated in graded concentrations of ethanol and propylene oxide, and embedded in EPON, Eponate 12 resin (Ted Pella, Redding, CA). Embedded specimens were sectioned at $600 \mathrm{~nm}$ with a diamond knife on a Sorvall MT-5000 ultramicrotome (Boeckeler Instruments, Tucson, AZ). Ribbons of sections were mounted on copper grids, stained with uranyl acetate and lead citrate, and examined with a Philips CM-100 transmission electron microscope. Photographs were obtained with a Kodak 1.6 Megaplus highresolution digital camera.

\section{RESULTS}

After 3 weeks of in vivo implantation, all the chambers were found to be completely filled with a "flap" of vascularized living tissue. The femoral artery and vein, which were running through the length of the tissue flaps, 
remained patent in all chambers. This was evidenced by the observation of active blood flow from the cut ends of the vessels on their transection at the proximal and distal ends of the chambers.

On explantation, each of the experimental constructs exhibited spontaneous contractility. When removed from the silicone chambers and placed in culture dishes filled with DMEM at $37^{\circ} \mathrm{C}$, the constructs flexed back and forth along their long axis, at approximately $0.5 \mathrm{~Hz}$. This spontaneous contractile activity lasted for approximately 5 min, ultimately slowing to a stop.

The stimulated contractility of the explanted tissue constructs was evaluated immediately after their explantation (Fig. 3) and the average twitch force of the constructs was found to be $263 \mu \mathrm{N}(n=5)$, with a maximum force recorded for one construct of $843 \mu \mathrm{N}$. One of the experimental constructs did not generate any measurable force. The time from harvest to contractility testing for this construct was delayed by about $4 \mathrm{~h}$ and may have contributed to loss of cell viability within the construct. The average specific force was found to be 2.03 $\mathrm{kPa}(n=5)$, with a maximum value of $6.45 \mathrm{kPa}$. The specific force was determined by normalizing the peak active force by the total cross-sectional area.

Six control chambers, manufactured without the addition of cardiac cells, were also harvested after 3 weeks of in vivo implantation around the femoral vessels. The femoral vessels remained patent in all cases. No spontaneous contraction occurred on explantation and there was no active force generation on electrical stimulation. Because the control constructs did not generate any mea- surable force on electrical stimulation, they were not tested any further.

To characterize the cardiac-like contractility characteristics of the experimental constructs, they were subjected to electrical pacing at frequencies from 1 to $20 \mathrm{~Hz}$. All other stimulation parameters remained constant. Active force was generated after each electrical stimulus delivered. Complete relaxation was noted between stimuli, with active forces returning back to baseline resting tension between contractions. A slight degradation in the magnitude of the force was noted over time at a stimulation frequency of $1 \mathrm{~Hz}$ (Fig. 4). This force degradation became increasingly rapid with increasing frequencies of stimulation, up to $20 \mathrm{~Hz}$.

The length-force relationship of the construct was evaluated for two constructs by recording the active force at incremental specimen lengths. Increasing the length of the constructs initially resulted in a proportional increase in force generation. This increase eventually reached a plateau, and then characteristically decreased proportionately with further incremental lengthening (Fig. 5).

The effect of the addition of exogenous calcium on contractility was tested on two constructs. At low calcium concentrations in the bath, the active force was not significantly different than the noise level. As the calcium concentration was increased, incremental additions of ionic calcium resulted in proportional rises in active force production (Fig. 6). A plateau was reached, at which point further addition of calcium did not produce an increase in active force production.

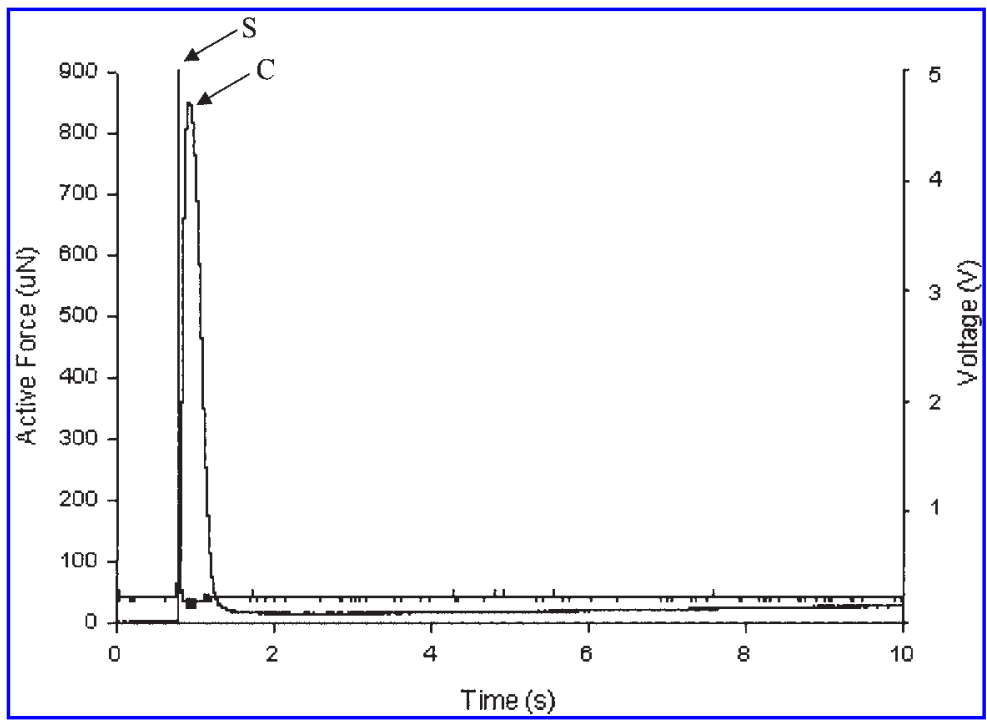

FIG. 3. Active force generation by constructs. Constructs were stimulated with $5 \mathrm{~V}$ at a 10 -ms pulse width (S) to elicit a twitch contraction (C). The resulting force tracings were recorded. The maximum active force generated by a single experimental construct was $843 \mu \mathrm{N}$ (shown here). Control constructs generated no measurable force. 


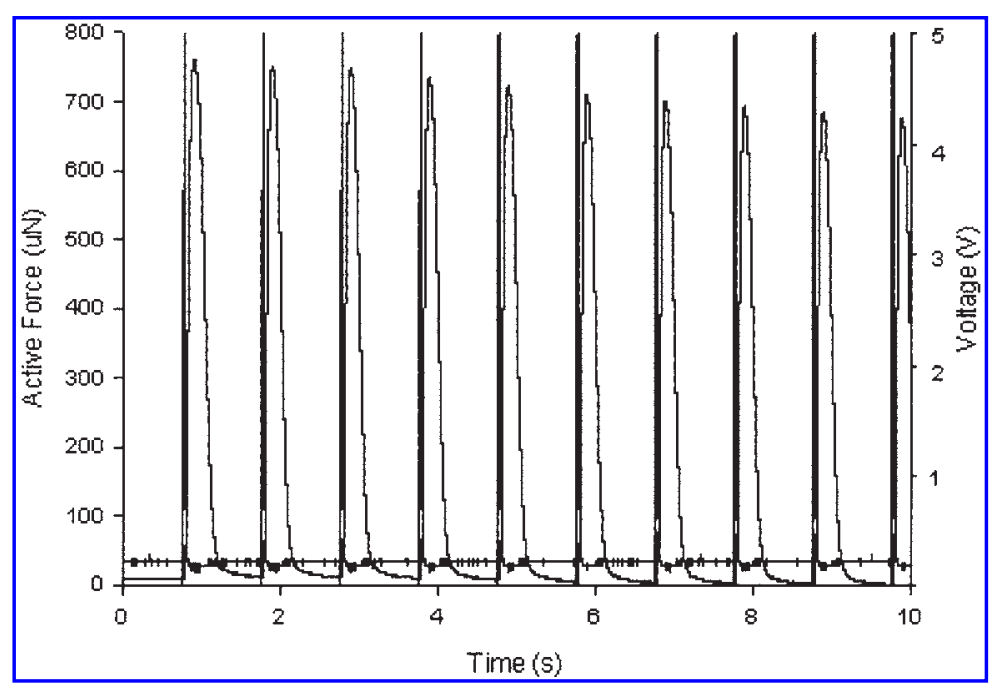

FIG. 4. Electrical pacing. Electrical pacing was successfully accomplished at frequencies from 1 to $20 \mathrm{~Hz}$, with a $1-\mathrm{Hz}$ tracing shown here. Note the complete relaxation of the construct to baseline force between stimulated contractions. A small diminution of force was noted over time, which increased more rapidly with increasing frequency of pacing. If the constructs were allowed to recover between testing sessions, the loss of active force was recovered.

The responsiveness of the constructs to epinephrine was evaluated for four constructs and a chronotropic effect was observed. At the start of epinephrine testing (after force testing as described above), the baseline spontaneous contractility of the constructs had ceased. However, with addition of epinephrine to the culture bath to a concentration of $0.2 \mu \mathrm{g} / \mathrm{mL}$, the constructs reinitiated spontaneous contractions. At some point (less than $60 \mathrm{~s}$ ) after the onset of spontaneous contractile activity, the contraction of the constructs became quite rapid (resembling tachyarrhythmia). The constructs exhibited this behavior for approximately 60-90 s, ultimately exiting this rapid contraction pattern and reentering a slower contraction pattern (Fig. 7). When the constructs exited the rapid contraction pattern, a decrease in the force production along with the decreased frequency of contraction was noted.

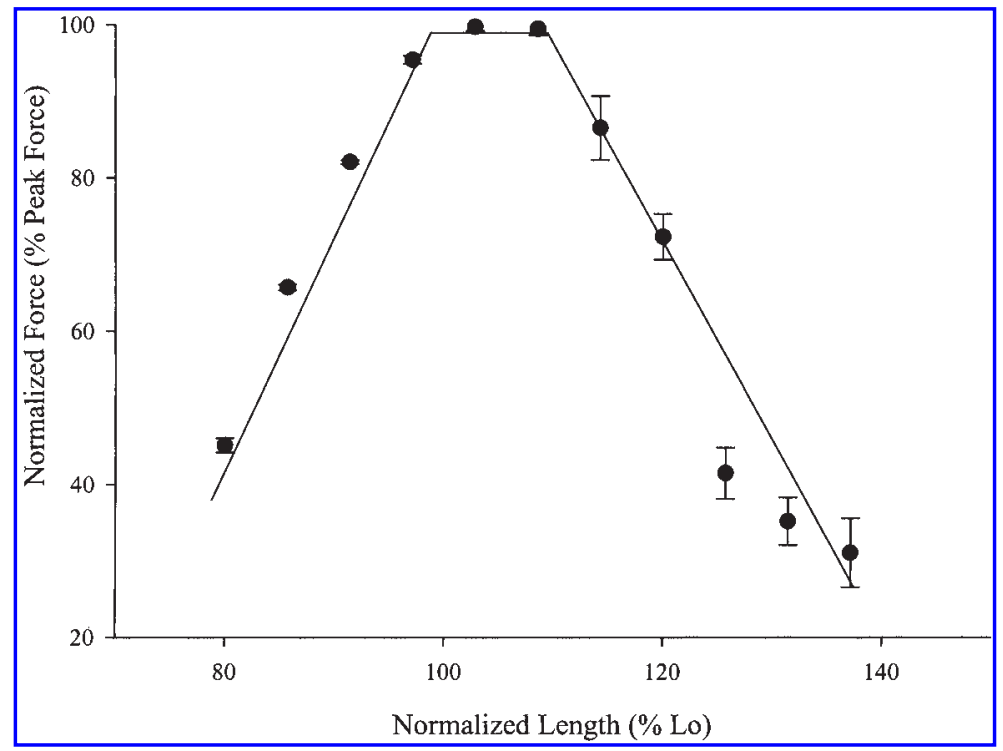

FIG. 5. Length-force relationship. The length of each construct was optimized for maximum force production. This value was considered $L_{\mathrm{o}}$ (optimal length) and the force measured at every other length was normalized to the force at $L_{\mathrm{o}}$. In two experimental constructs, multiple measurements were recorded over a range of adjusted lengths to fully characterize the length-force relationship. The curve shown is one of two constructs tested in this manner and is representative of the other (not shown). Values shown represent the mean and standard deviation of five force readings for a single construct. 


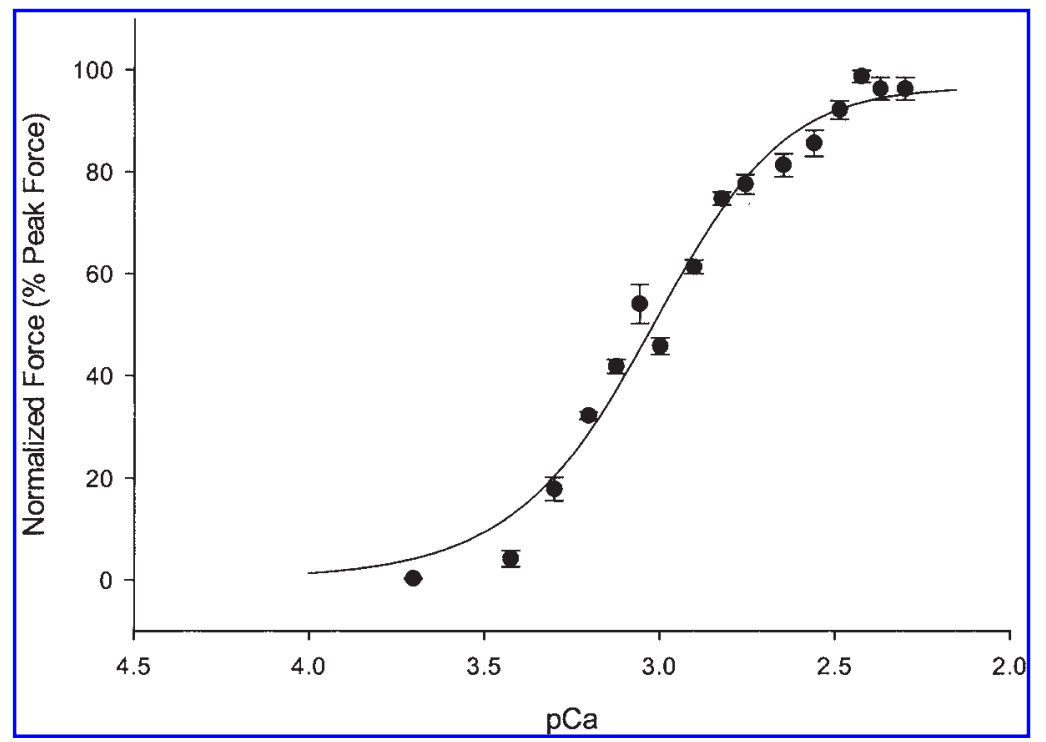

FIG. 6. Inotropic response to ionic calcium. After complete removal of calcium from the system, calcium was reintroduced incrementally and force production was tested in two constructs. The peak active force was plotted at each new calcium concentration. The curve shown is one of two constructs tested in this manner and is representative of the other (not shown). Values shown represent the mean and standard deviation of five force readings for a single construct.

Experimental constructs were examined histologically. H\&E staining showed large areas of easily recognizable muscle tissue permeated by multiple vascular channels of all sizes (Fig. 8A and B). Immunohistochemical stain- ing for vWF highlighted the endothelium of this rich vascular network, which was filled with red blood cells (Fig. 8C and D). Electron micrographs of the constructs showed the presence of well-organized contractile pro-

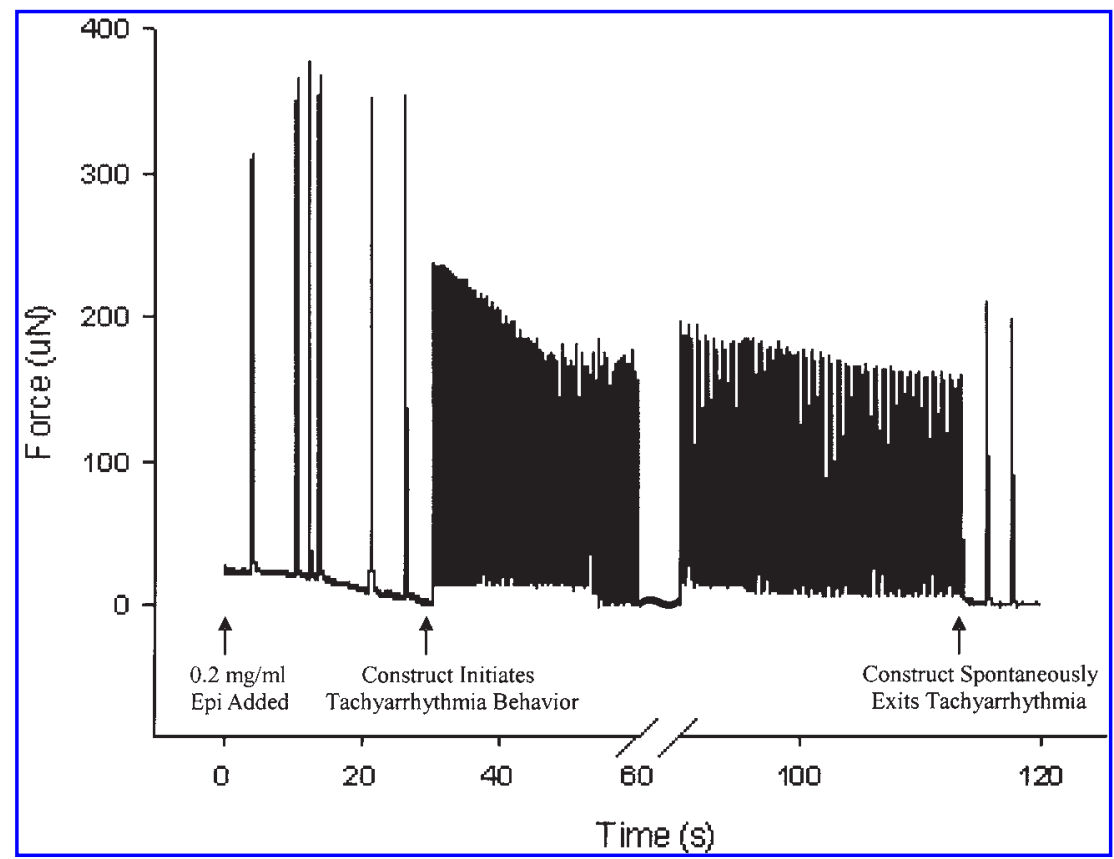

FIG. 7. Chronotrophic response of a construct to epinephrine. At the start of epinephrine testing, baseline spontaneous contractility of the constructs had decreased to zero. The addition of epinephrine initiated spontaneous contractions and the construct generated approximately six contractions in a 30-s time frame. Approximately $30 \mathrm{~s}$ after the onset of spontaneous contractile activity, the construct generated a rapid pattern of contraction that lasted for another $90 \mathrm{~s}$. After this time, the construct spontaneously exited this high rate of contraction and reentered the slower rate of contraction observed directly after the addition of epinephrine. The behavior shown is representative of four constructs tested in this manner. 


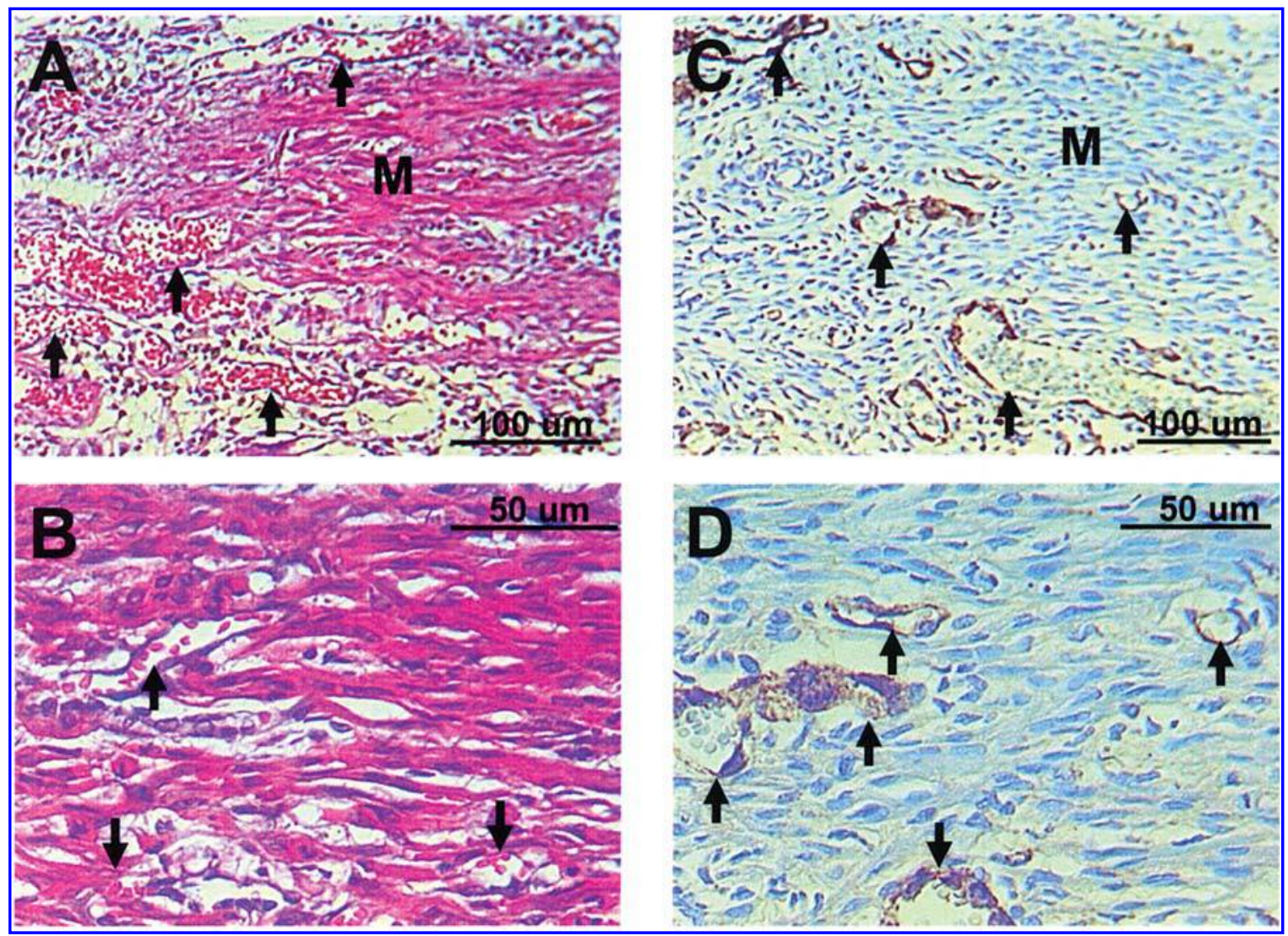

FIG. 8. Histology of the constructs. (A and B) H\&E staining of a section through the center of a construct demonstrates large areas of viable muscle tissue (M). Multiple vascular channels of all sizes permeate the construct (arrows), and can be seen to be filled with red blood cells. (C and D) von Willebrand staining highlights the endothelial lining within the newly formed vascular channels (arrows).

teins and equally spaced $\mathrm{Z}$ lines (Fig. 9A). The presence of intercalated disks was also confirmed (Fig. 9B).

\section{DISCUSSION}

Several methods have been successfully employed to promote therapeutic angiogenesis in tissue engineering, thus enhancing the ability to engineer three-dimensional tissues. Specifically, two models of in vivo angiogenesis have shown promise as potential platforms for three-dimensional tissue engineering. ${ }^{30-35} \mathrm{We}$ chose to investigate a modification of these models as a potential base for engineering cardiac tissue. There are several key features of the current method that allow the formation of contractile three-dimensional cardiac tissue. The incorporation of a vascular pedicle within the construct induces angiogenesis, resulting in complete and thorough vascularization of the tissues. Use of the silicone tube keeps the introduced cells in relative isolation and confines the final construct to a useable and testable form. This also holds the cardiac cells in close proximity to one another, allowing them to organize and form intracellular connections. Spontaneous matrix deposition within the silicone tube provides mechanical integrity to the cardiac tissue construct.

Histologic evaluation confirmed neovascularization throughout the constructs. Matrix deposition in the form of collagen was also present, presumably laid down by fibroblasts introduced with the cardiac myocytes. Viable cardiac myocytes were confirmed in all chambers on H\&E staining. Also interesting were the electron micrographic images. Well-organized contractile elements, equally spaced $\mathrm{Z}$ lines, and intercalated disks give specific evidence of cardiac muscle machinery and organization.

The cardiac tissue constructs were electrically excitable and were capable of generating a peak active of $843 \mu \mathrm{N}$ and a maximum specific force of $6.45 \mathrm{kPa}$. These results show an approximate 10 -fold increase over our previous in vitro work. ${ }^{20}$ However, an adult rat papillary muscle generates a peak active of approximately 8130 $\mu \mathrm{N}$ and a specific force of about $44.4 \mathrm{kPa} .{ }^{39}$ Thus, the force-generating capability of these engineered con- 


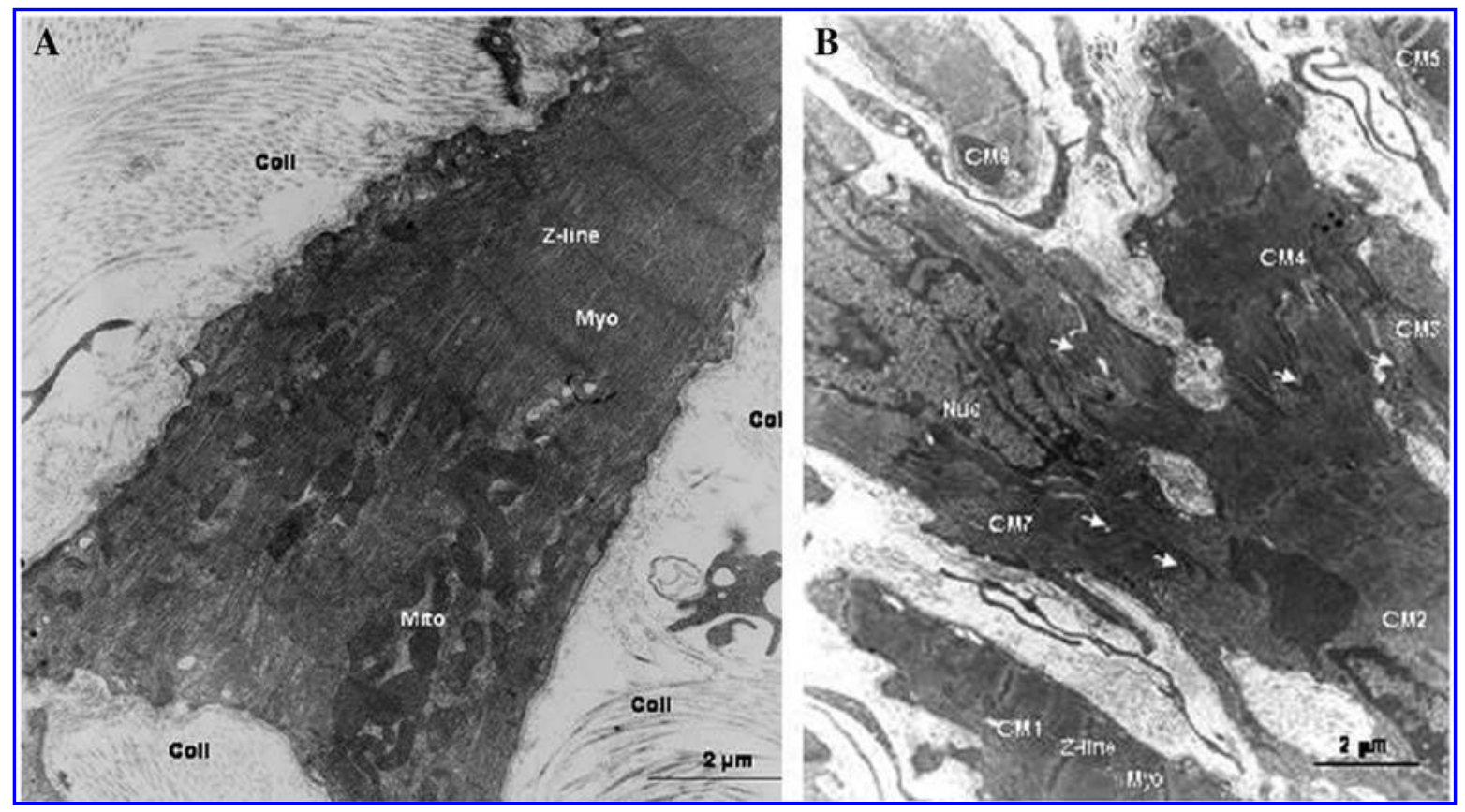

FIG. 9. Electron micrographs of the constructs. (A) EM section of a single cardiac myocyte within the construct showing the presence of well-aligned myofilaments (Myo) and equally spaced Z lines (Z-line). Also evident are abundant amounts of mitochondria (Mito), which are closely associated with the myofilaments. The presence of collagen (Coll) fibers are also evident. (B) EM section showing the presence of seven cardiac myocytes (CM1-7). A large number of intercalated disks (arrows) have formed between myocytes. Also evident are the nuclei (Nuc) of the cardiac myocytes as well as myofilaments with associated mitochondria.

structs is still an order of magnitude less than that for normal cardiac tissue. This could be due to the early developmental stage of the neonatal cardiac myocytes utilized in this study. Developmentally immature cardiomyocytes are known to contain significantly smaller amounts of contractile proteins per unit cross-section of cardiac tissue. ${ }^{40}$ Another contributing factor could be the lack of functional organization of extracellular matrix components. In the current model, we allowed spontaneous distribution and organization of the extracellular matrix, which may develop significantly different from the normal architecture of cardiac muscle.

We subjected the constructs to electrical pacing and found that they were capable of generating repetitive contractions at frequencies of 1-20 Hz. During the course of electrical pacing, we observed a decrease in the peak active force with each subsequent active contraction. This is indicative of muscle fatigue and may be due to nutrient deprivation during evaluation in vitro. However, the constructs completely relaxed between contractions, similar to normal cardiac muscle. In addition, the constructs exhibited a length-force relationship characteristic of muscle tissue, with force tracings showing an ascending limb, a plateau region, and a descending limb with increasing length.

The calcium and epinephrine responsiveness of the constructs indicates they are of cardiac origin. Explanted constructs exhibit a sigmoidal responsiveness to external calcium. The $\mathrm{pCa}_{1 / 2}$ of the constructs was found to be 3.04. The $\mathrm{pCa}_{1 / 2}$ of mammalian cardiac tissue has been reported in the range of 5.9 to $7.0 .^{41}$ Our constructs, therefore, exhibit a decreased sensitivity to calcium versus normal cardiac tissue. However, once a threshold was obtained, the constructs exhibited similar increases in force production per unit rise in calcium as normal cardiac tissue. The responsiveness to external calcium is an indicator of the presence of functional calcium-handling machinery. The constructs also exhibited a chronotropic response to epinephrine, as one would expect in tissues of cardiac origin.

In this study we present data to demonstrate the formation of vascularized, three-dimensional cardiac tissue. The newly formed constructs resemble normal myocardial tissue in terms of their contractile properties, responsiveness to epinephrine and ionic calcium, length-force relationship, and morphological characteristics. The method utilized in this study to engineer cardiac tissue allows for the incorporation of a vascular network throughout the construct. The vascular network promotes the survival of cells within the construct and allows for an improvement in active force generation compared with our previous development of in vitro, avascular constructs.

Theoretically, these tissue constructs would be microsurgically transferable, as anastomosis of the vessels of 
the pedicle to a distant site or to another animal would be easily performed. The model allows use of any of a number of different vascular sites, as well. Further studies will focus on use of this tissue both as a "patch" replacement for damaged myocardium and as a flowthrough construct.

\section{CONCLUSION}

This study demonstrates the in vivo survival, vascularization, organization, and functionality of transplanted myocardial cells. The model was shown to be an excellent platform for engineering three-dimensional cardiac tissue in vivo.

\section{ACKNOWLEDGMENT}

The authors thank Dr. Krystyna A. Pasyk, M.D., Ph.D., for assistance with the electron micrographs presented in this study.

\section{REFERENCES}

1. American Heart Association. Heart Disease and Stroke Statistics, 2005. www.americanheart.org/downloadable/heart/ 1105390918119HDSStats2005/update.pdf

2. Goldstein, S. Heart failure therapy at the turn of the century. Heart Failure Rev. 6, 7, 2001.

3. Stevenson, L.W., and Kormos, R.L. Mechanical cardiac support 2000: Current applications and future trial design. J. Heart Lung Transplant. 20, 1, 2001.

4. Miniati, D.N., and Robbins, R.C. Heart transplantation: A thirty-year perspective. Annu. Rev. Med. 53, 189, 2002.

5. Stevenson, L.W., Warner, S.L., Steimyle, A.E., Fonarow, G.C., Hamilton, M.A., Moriguchi, J.D., Kobashigawa, J.A., Tillisch, J.H., Drinkwater, D.C., and Laks, H. The impending crisis awaiting cardiac transplantation: Modeling a solution based on selection. Circulation 89, 450, 1994.

6. Shimizu, T., Yamato, M., Kikuchi, A., and Okano, T. Twodimensional manipulation of cardiac myocyte sheets utilizing temperature-responsive culture dishes augments the pulsatile amplitude. Tissue Eng. 7, 141, 2001.

7. Shimizu, T., Yamato, M., Isoi, Y., Akutsu, T., Setomaru, T., Abe, K., Kikuchi, A., Umezu, M., and Okano, T. Fabrication of pulsatile cardiac tissue grafts using a novel 3dimensional cell sheet manipulation technique and temperature-responsive cell culture surfaces. Circ. Res. 90, e40, 2002.

8. Shimizu, T., Yamato, M., Akutsu, T., Shibata, T., Isoi, Y., Kikuchi, A., Umezu, M., and Okano, T. Electrically communicating three-dimensional cardiac tissue mimic fabricated by layered cultured cardiomyocyte sheets. J. Biomed. Mater. Res. 60, 110, 2002.

9. Bursac, N., Papadaki, M., Cohen, R.J., Schoen, F.J., Eisenberg, S.R., Carrier, R., Vunjak-Novakovic, G., and Freed, L.E. Cardiac muscle tissue engineering: Toward an in vitro model for electrophysiological studies. Am. J. Physiol. 277, H433, 1999.

10. Carrier, R.L., Papadaki, M., Rupnick, M., Schoen, F.J., Bursac, N., Langer, R., Freed, L.E., and Vunjak-Novakovic, G. Cardiac tissue engineering: Cell seeding, cultivation parameters, and tissue construct characterization. Biotechnol. Bioeng. 64, 580, 1999.

11. Papadaki, M., Bursac, N., Langer, R., Merok, J., VunjakNovakovic, G., and Freed, L.E. Tissue engineering of functional cardiac muscle: Molecular, structural, and electrophysiological studies. Am. J. Physiol. Heart Circ. Physiol. 280, H168, 2001.

12. Li, R.K., Jia, Z.Q., Weisel, R.D., Mickle, D.A., Choi, A., and Yau, T.M. Survival and function of bioengineered cardiac grafts. Circulation 100(Suppl.), II-63, 1999.

13. Li, R.K., Yau, T.M., Weisel, R.D., Mickle, D.A., Sakai, T., Choi, A., and Jia, Z.Q. Construction of a bioengineered cardiac graft. J. Thorac. Cardiovasc. Surg. 119, 368, 2000.

14. Sakai, T., Li, R.K., Weisel, R.D., Mickle, D.A., Kim, E.T., Jia, Z.Q., and Yau, T.M. The fate of a tissue-engineered cardiac graft in the right ventricular outflow tract of the rat. J. Thorac. Cardiovasc. Surg. 121, 932, 2001.

15. Leor, J., Aboulafia-Etzion, S., Dar, A., Shapiro, L., Barbash, I.M., Battler, A., Granot, Y., and Cohen, S. Bioengineered cardiac grafts: A new approach to repair the infarcted myocardium? Circulation 102(Suppl.), III-56, 2000.

16. Eschenhagen, T., Fink, C., Remmers, U., Scholz, H., Wattchow, J., Weil, J., Zimmermann, W., Dohmen, H.H., Schafer, H., Bishopric, N., Wakatsuki, T., and Elson, E.L. Three-dimensional reconstitution of embryonic cardiomyocytes in a collagen matrix: A new heart muscle model system. FASEB J. 11, 683, 1997.

17. Souren, J.E., Schneijdenberg, C., Verkleij, A.J., and Van Wijk, R. Factors controlling the rhythmic contraction of collagen gels by neonatal heart cells. In Vitro Cell. Dev. Biol. 28A, 199, 1992.

18. Zimmermann, W.H., Fink, C., Kralisch, D., Remmers, U., Weil, J., and Eschenhagen, T. Three-dimensional engineered heart tissue from neonatal rat cardiac myocytes. Biotechnol. Bioeng. 68, 106, 2000.

19. Zimmermann, W.H., Schneiderbanger, K., Schubert, P., Didie, M., Munzel, F., Heubach, J.F., Kostin, S., Neuhuber, W.L., and Eschenhagen, T. Tissue engineering of a differentiated cardiac muscle construct. Circ. Res. 90, 223, 2002.

20. Baar, K., Birla, R., Boluyt, M.O., Borschel, G.H., Arruda, E.M., and Dennis, R.G. Heart muscle by design: Self-organization of rat cardiac cells into contractile 3-D cardiac tissue. FASEB J. 19, 275, 2005.

21. Colton, C.K. Implantable biohybrid artificial organs. Cell Transplant. 4, 415, 1995.

22. Hockel, M., Schlenger, K., Doctrow, S., Kissel, T., and Vaupel, P. Therapeutic angiogenesis. Arch. Surg. 128, 423, 1993.

23. Soker, S., Machado, M., and Atala, A. Systems for therapeutic angiogenesis in tissue engineering. World J. Urol. 18, 10, 2000.

24. Epstein, S.E., Fuchs, S., Zhou, Y.F., Baffour, R., and Kornowski, R. Therapeutic interventions for enhancing collateral development by administration of growth factors: 
Basic principles, early results and potential hazards. Cardiovasc. Res. 49, 532, 2001.

25. Shea, L.D., Smiley, E., Bonadio, J., and Mooney, D.J. DNA delivery from polymer matrices for tissue engineering. Nat. Biotechnol. 17, 551, 1999.

26. Holder, W.D., Gruber, H.E., Roland, W.D., Moore, A.L., Culberson, C.R., Loebsack, A.B., Burg, K.J.L., and Mooney, D.J. Increased vascularization and heterogeneity of vascular structures occurring in polyglycolide matrices containing aortic endothelial cells implanted in the rat. Tissue Eng. 3, 149, 1997.

27. Mikos, A.G., Sarakinos, G., Lyman, M.D., Ingber, D.E., Vacanti, J.P., and Langer, R. Prevascularization of porous biodegradable polymers. Biotechnol. Bioeng. 42, 716, 1993.

28. Griffith, L.G., Wu, B., Cima, M.J., Powers, M.J., Chaignaud, B., and Vacanti, J.P. In vitro organogenesis of liver tissue. Ann. N.Y. Acad. Sci. 831, 382, 1997.

29. Hollister, S.J., Levy, R.A., Chu, T.M., Halloran, J.W., and Feinberg, S.E. An image-based approach for designing and manufacturing craniofacial scaffolds. Int. J. Oral Maxillofac. Surg. 29, 67, 2000.

30. Cronin, K.J., Messina, A., Knight, K.R., Cooper-White, J.J., Stevens, G.W., Penington, A.J., and Morrison, W.A. New murine model of spontaneous autologous tissue engineering, combining an arteriovenous pedicle with matrix materials. Plast. Reconstr. Surg. 113, 260, 2004.

31. Cassell, O.C., Morrison, W.A., Messina, A., Penington, A.J., Thompson, E.W., Stevens, G.W., Perera, J.M., Kleinman, H.K., Hurley, J.V., Romeo, R., and Knight, K.R. The influence of extracellular matrix on the generation of vascularized, engineered, transplantable tissue. Ann. N.Y. Acad. Sci. 944, 429, 2001.

32. Mian, R., Morrison, W.A., Hurley, J.V., Penington, A.J., Romeo, R., Tanaka, Y., and Knight, K.R. Formation of new tissue from an arteriovenous loop in the absence of added extracellular matrix. Tissue Eng. 6, 595, 2000.

33. Tanaka, Y., Tsutsumi, A., Crowe, D.M., Tajima, S., and Morrison, W.A. Generation of an autologous tissue (matrix) flap by combining an arteriovenous shunt loop with artificial skin in rats: Preliminary report. Br. J. Plast. Surg. 53, 51, 2000.

34. Brown, D., Cronin, K., Morrison, W., Keramidaris, E., Romeo-Meeuw, R., Penington, A.J., and Harrison, L.C. Developing an in vivo, tissue-engineered, vascularized, pancreatic organoid in the mouse. (Submitted 2005).

35. Mian, R.A., Knight, K.R., Penington, A.J., Hurley, J.V., Messina, A., Romeo, R., and Morrison, W.A. Stimulating effect of an arteriovenous shunt on the in vivo growth of isografted fibroblasts: A preliminary report. Tissue Eng. 7, 73, 2001.

36. Boluyt, M.O., Zheng, J.S., Younes, A., Long, X., O’Neill, L., Silverman, H., Lakatta, E.G., and Crow, M.T. Rapamycin inhibits $\alpha_{1}$-adrenergic receptor-stimulated cardiac myocyte hypertrophy but not activation of hypertrophy-associated genes: Evidence for involvement of p70 S6 kinase. Circ. Res. 81, 176, 1997.

37. Dennis, R.G., and Kosnik, P.E. Excitability and isometric contractile properties of mammalian skeletal muscle constructs engineered in vitro. In Vitro Cell. Dev. Biol. Anim. 36, 327, 2000.

38. Dennis, R.G., Kosnik, P.E., Gilbert, M.E., and Faulkner, J.A. Excitability and contractility of skeletal muscle engineered from primary cultures and cell lines. Am. J. Physiol. Cell Physiol. 280, C288, 2001.

39. Layland, J., Young, I.S., and Altringham, J.D. The effect of cycle frequency on the power output of rat papillary muscle in vitro. J. Exp. Biol. 198, 1035, 1995.

40. Friedman, W.F. The intrinsic physiologic properties of the developing heart. Prog. Cardiovasc. Dis. 15, 87, 1972.

41. Bers, D.M. Excitation-Contraction Coupling and Cardiac Contractile Force. Norwell, MA: Kluwer Academic, 2002.

Address reprint requests to: David L. Brown, M.D. 2130 Taubman Center 1500 East Medical Center Drive Ann Arbor, MI 48109-0340

E-mail: davbrown@umich.edu 


\section{This article has been cited by:}

1. Ravi K. Birla, Vikas Dhawan, Douglas E. Dow, Yen-Chih Huang, David L. Brown. 2009. Cardiac cells implanted into a cylindrical, vascularized chamber in vivo: pressure generation and morphology. Biotechnology Letters 31:2, 191-201. [CrossRef]

2. Ravi Birla, Vikas Dhawan, Yen-Chih Huang, Ian Lytle, Khajohn Tiranathanagul, David Brown. 2008. Force Characteristics of In Vivo Tissue-engineered Myocardial Constructs Using Varying Cell Seeding Densities. Artificial Organs 32:9, 684-691. [CrossRef]

3. Yen-Chih Huang, Luda Khait, Ravi K. Birla. 2008. Modulating the Functional Performance of Bioengineered Heart Muscle Using Growth Factor Stimulation. Annals of Biomedical Engineering 36:8, 1372-1382. [CrossRef]

4. R. K. Birla, Y. C. Huang, R. G. Dennis. 2008. Effect of streptomycin on the active force of bioengineered heart muscle in response to controlled stretch. In Vitro Cellular \& Developmental Biology - Animal 44:7, 253-260. [CrossRef]

5. Nicole R. Blan, Ravi K. Birla. 2008. Design and fabrication of heart muscle using scaffold-based tissue engineering. Journal of Biomedical Materials Research Part A 86A:1, 195-208. [CrossRef]

6. Tamer A.E. Ahmed, Emma V. Dare, Max Hincke . 2008. Fibrin: A Versatile Scaffold for Tissue Engineering ApplicationsFibrin: A Versatile Scaffold for Tissue Engineering Applications. Tissue Engineering Part B: Reviews 14:2, 199-215. [Abstract] [PDF] [PDF Plus]

7. Louise Hecker, Luda Khait, Desmond Radnoti, Ravi Birla. 2008. Development of a Microperfusion System for the Culture of Bioengineered Heart Muscle. ASAIO Journal 54:3, 284-294. [CrossRef]

8. Luda Khait, Louise Hecker, Desmond Radnoti, Ravi K. Birla. 2008. Micro-Perfusion for Cardiac Tissue Engineering: Development of a Bench-Top System for the Culture of Primary Cardiac Cells. Annals of Biomedical Engineering 36:5, 713-725. [CrossRef]

9. Tamer A.E. Ahmed , Emma V. Dare , Max Hincke . Fibrin: A Versatile Scaffold for Tissue Engineering ApplicationsFibrin: A Versatile Scaffold for Tissue Engineering Applications. Tissue Engineering Part B: Reviews, ahead of print. [Abstract] [PDF] [PDF Plus]

10. Luda Khait, Louise Hecker, Nicole R. Blan, Garrett Coyan, Francesco Migneco, Yen-Chih Huang, Ravi K. Birla. 2008. Getting to the Heart of Tissue Engineering. Journal of Cardiovascular Translational Research 1:1, 71-84. [CrossRef]

11. Mark J. Mondrinos, Sirma H. Koutzaki, Honesto M. Poblete, M. Cecilia Crisanti, Peter I. Lelkes , Christine M. Finck . 2008. In Vivo Pulmonary Tissue Engineering: Contribution of Donor-Derived Endothelial Cells to Construct Vascularization*In Vivo Pulmonary Tissue Engineering: Contribution of Donor-Derived Endothelial Cells to Construct Vascularization*. Tissue Engineering Part A 14:3, 361-368. [Abstract] [PDF] [PDF Plus]

12. Mark J. Mondrinos, Sirma H. Koutzaki, Honesto M. Poblete, M. Cecilia Crisanti , Peter I. Lelkes, Christine M. Finck . In Vivo Pulmonary Tissue Engineering: Contribution of Donor-Derived Endothelial Cells to Construct Vascularization*In Vivo Pulmonary Tissue Engineering: Contribution of Donor-Derived Endothelial Cells to Construct Vascularization*. Tissue Engineering, ahead of print. [Abstract] [PDF] [PDF Plus]

13. Vikas Dhawan, Ian F. Lytle, Douglas E. Dow, Yen-Chih Huang, David L. Brown . 2007. Neurotization Improves Contractile Forces of Tissue-Engineered Skeletal MuscleNeurotization Improves Contractile Forces of Tissue-Engineered Skeletal Muscle. Tissue Engineering 13:11, 2813-2821. [Abstract] [PDF] [PDF Plus]

14. H. Jawad, N. N. Ali, A.R. Lyon, Q. Z. Chen, S. E. Harding, A. R. Boccaccini. 2007. Myocardial tissue engineering: a review. Journal of Tissue Engineering and Regenerative Medicine 1:5, 327-342. [CrossRef]

15. R.K. Birla , Y.C. Huang , R.G. Dennis . 2007. Development of a Novel Bioreactor for the Mechanical Loading of Tissue-Engineered Heart MuscleDevelopment of a Novel Bioreactor for the Mechanical Loading of Tissue-Engineered Heart Muscle. Tissue Engineering 13:9, 2239-2248. [Abstract] [PDF] [PDF Plus]

16. Marie-Noëlle Giraud, Christine Armbruster, Thierry Carrel, Hendrik T. Tevaearai . 2007. Current State of the Art in Myocardial Tissue EngineeringCurrent State of the Art in Myocardial Tissue Engineering. Tissue Engineering 13:8, 1825-1836. [Abstract] [PDF] [PDF Plus]

17. L Khait, Ravi K Birla. 2007. Cell-based cardiac pumps and tissue-engineered ventricles. Regenerative Medicine 2:4, 391-406. [CrossRef]

18. Jana Dengler, Milica Radisic. 2007. Tissue engineering approaches for the development of a contractile cardiac patch. Future Cardiology 3:4, 425-434. [CrossRef]

19. Robert E. Akins , Kara Gratton, Emilio Quezada, Heather Rutter, Takeshi Tsuda, Patricia Soteropoulos . 2007. Gene Expression Profile of Bioreactor-Cultured Cardiac Cells: Activation of Morphogenetic Pathways for Tissue EngineeringGene Expression 
Profile of Bioreactor-Cultured Cardiac Cells: Activation of Morphogenetic Pathways for Tissue Engineering. DNA and Cell Biology 26:6, 425-434. [Abstract] [PDF] [PDF Plus]

20. Louise Hecker, Ravi K Birla. 2007. Engineering the heart piece by piece: state of the art in cardiac tissue engineering. Regenerative Medicine 2:2, 125-144. [CrossRef]

21. Khajohn Tiranathanagul, Vikas Dhawan, Ian F. Lytle, Wen Zhang, Gregory H. Borschel, Deborah A. Buffington, Evangelos Tziampazis, David L. Brown, H David Humes. 2007. Tissue Engineering of an Implantable Bioartificial Hemofilter. ASAIO Journal 53:2, 176-186. [CrossRef]

22. Marie-Noëlle Giraud, Christime Armbuster, Thierry Carrel, Hendrik T. Tevaearai. 2007. Current State of the Art in Myocardial Tissue Engineering. Tissue Engineering, ahead of print070126052142001. [CrossRef]

23. Lisa E. Freed, Farshid Guilak, X. Edward Guo, Martha L. Gray, Robert Tranquillo, Jeffrey W. Holmes, Milica Radisic, Michael V. Sefton , David Kaplan , Gordana Vunjak-Novakovic . 2006. Advanced Tools for Tissue Engineering: Scaffolds, Bioreactors, and SignalingAdvanced Tools for Tissue Engineering: Scaffolds, Bioreactors, and Signaling. Tissue Engineering 12:12, 3285-3305. [Abstract] [PDF] [PDF Plus]

24. A. D. Bach, A. Arkudas, J. Tjiawi, E. Polykandriotis, U. Kneser, R. E. Horch, J. P. Beier. 2006. A new approach to tissue engineering of vascularized skeletal muscle. Journal of Cellular and Molecular Medicine 10:3, 716-726. [CrossRef] 